\title{
Rapid apparent polar wandering of South China during the latest Paleozoic and early Mesozoic: a paleomagnetic study of Upper Permian limestones from Guizhou province
}

\author{
Zhongmin Wang and Rob Van der Voo \\ Department of Geological Sciences, University of Michigan, Ann Arbor, MI 48109-1063, USA
}

(Received October 23, 1992; revised version accepted February 25, 1993)

\begin{abstract}
Wang, Z. and Van der Voo, R., 1993. Rapid apparent polar wandering of South China during the latest Paleozoic and early Mesozoic: a paleomagnetic study of Upper Permian limestones from Guizhou province. Tectonophysics, 222: $165-176$.

The lower part of Upper Permian ( $\sim 265 \mathrm{Ma}$ ) marine platform limestones in Guizhou province (South China Block) was sampled for paleomagnetic study. A total of 24 samples from 4 sites was collected. Progressive thermal demagnetization isolated single characteristic component magnetizations from 21 samples. The samples show mixed, but dominantly normal polarities. The mean direction is $46 / 23$ (in-situ) and 53/11 (tilt-corrected), yielding a pole position of 34N, 208E. IRM acquisition experiments suggest that the magnetizations are carried by magnetite. SEM images of polished thin-sections show that the magnetite has replaced pyrite, indicating a secondary (diagenetic) origin for the magnetite. Considering the dominant normal polarity and by comparison with paleomagnetic results of Permian and younger ages for South China, we infer that these Upper Permian limestones in Guizhou province have been remagnetized during the latest Permian or Early Triassic. A review of the paleomagnetic data reported thus far for the Emeishan Basalts in different localities shows that the results from these Upper Permian rocks in general fall into three groups: one group (A) resembles the mean characteristic direction of our limestones; the second group $(B)$ has yielded directions in agreement with those of the Triassic; and the third group (C) conforms to the directions obtained from the Late Triassic/Jurassic remagnetization data in some Paleozoic and Triassic rocks of South China. SEM observations of Emeishan Basalts thin-sections indicate that the A group directions most likely represent the primary magnetizations, while the $\mathbf{B}$ group directions are remagnetizations. A late Paleozoic/early Mesozoic apparent polar wander path for South China can thus be constructed by connecting these poles. Paleopoles calculated from northerly folding-associated remagnetizations (C) also fall on this path and are the youngest. This apparent polar wander path points to larger-scale rotations of the South China Block during the late Paleozoic and early Mesozoic than previously thought.
\end{abstract}

\section{Introduction}

The South China Block (SCB) is one of the major blocks of Asia; it has been the subject of several paleomagnetic studies although its Phanerozoic Apparent Polar Wander Path (APWP) is still incompletely known. One of the best-known segments of the APWP appcars to bc the Permian, but as this paper will demonstrate, even here there are problems. The Upper Permian Emeishan Basalts and the top part of the

Correspondence to $\mathrm{Z}$. Wang.
Upper Permian sedimentary rocks have been the focus of many paleomagnetic studies in South China (e.g., McElhinny et al., 1981; Chan et al., 1984; Zhang, 1984; Huang et al., 1986; Zhou et al., 1986; Zhao and Coe, 1987; Heller et al., 1988; Lin, 1989; Steiner et al., 1989; Van der Voo et al., 1993). The published studies from the Emeishan Basalts (Table 1) have obtained seemingly coherent characteristic magnetizations with either north-northeasterly or west-southwesterly directions. The inclinations are all shallow and indeed it is little doubted that South China occupied an equatorial latitude during the Late Permian. A non-antipodal feature of the normal and reversed 
directions, however, results from variable northerly to northeasterly/southwesterly declinations (Zhou et al., 1986; Lin, 1989; Van der Voo et al., 1993). This has naturally led to uncertainties about the validity of the Emeishan paleopoles. Figure 1 illustrates the sampling localities and the normal and reversed directions reported in the previous studies. Several causes of this non-antipodality, such as regional rotations, composite magnetizations, age differences between the flows studied, (magnetic) orientation errors of strongly magnetized basalts, remagnetizations of either the northerly or the west-southwesterly magnetizations, or asymmetric reversals of the geomagnetic field, have been hypothesized although they thus far have all been rather speculative. A few of these - rotations, composite magnetizations and age differences of flows studied - have virtually been ruled out by Van der Voo et al. (1993). Lin (1989) has speculated, although on a fairly weak basis, that the normal-polarity directions are partial to complete remagnetizations, given that they yield a paleopole that appears to be younger than the paleopole calculated for reversed rocks and

\section{TABLE 1}

Summary of paleomagnetic results for the Late Permian and the early Mesozoic of the South China Block

\begin{tabular}{|c|c|c|c|c|c|c|}
\hline No. & Locality & $N(n)$ & $\mathrm{Decl} /$ Incl & $A_{95}$ & Paleopole & Reference \\
\hline \multicolumn{7}{|c|}{ The Emeishan Basalts and the limestone of this study } \\
\hline \multicolumn{7}{|c|}{ Group $A$} \\
\hline 1 & Zhijin & 4 & $53 / 11$ & 14.7 & $34 \mathrm{~N} 208 \mathrm{E}$ & This study \\
\hline 2 & Bingchuan & 3 & $241 /$ & 24.8 & $25 \mathrm{~N} 204 \mathrm{E}$ & Huang et al. (1986) \\
\hline 3 & Kunming & (2) & $244 / 3$ & - & $23 \mathrm{~N} 206 \mathrm{E}$ & Van der Voo et al. (1993) \\
\hline 4 & Dongchuan & 2 & $53 /-26$ & - & $25 \mathrm{~N} 224 \mathrm{E}$ & Huang et al. (1986)* \\
\hline 5 & Panxi & 4 & $50 /-12$ & 16.0 & $31 \mathrm{~N} 218 \mathrm{E}$ & Zhou et al. (1986)\# \\
\hline \multicolumn{7}{|c|}{ Group B } \\
\hline 6 & Emei & (6) & $23 /$ & 19.5 & $54 \mathrm{~N} 242 \mathrm{E}$ & Chan et al. (1984) \\
\hline 7 & Huidong & 7 & $23 /-5$ & 10.0 & $54 \mathrm{~N} 242 \mathrm{E}$ & Huang et al. (1986) \\
\hline 8 & Dongchuan & 3 & $24 /-7$ & 16.0 & $52 \mathrm{~N} 241 \mathrm{E}$ & Huang et al. (1986)* \\
\hline 9 & Emei & 20 & $21 /-8$ & 3.3 & $51 \mathrm{~N} 248 \mathrm{E}$ & Zhang (1984) \\
\hline 10 & Emei & 22 & $18 /-7$ & 6.2 & $54 \mathrm{~N} 252 \mathrm{E}$ & McFlhinny et al. (1981) \\
\hline 11 & Emei & 32 & $21 /-13$ & 4.0 & $49 \mathrm{~N} 251 \mathrm{E}$ & Zhao and Coe (1987) \\
\hline 12 & Kunming & 10 & $26 /-12$ & 6.1 & $50 \mathrm{~N} 241 \mathrm{E}$ & Van der Voo et al. (1993) \\
\hline
\end{tabular}

\section{Folding-associated remagnetizations}

\section{Group C}

$\begin{array}{llrlrlll}13 & \text { Nanjing } & 21 & 352 / 12 & 6.5 & 56 \mathrm{~N} 314 \mathrm{E} & \text { Wang and Van der Voo (1993) } \\ 14 & \text { Guizhou } & 9 & 353 / & 15 & 5.5 & 70 \mathrm{~N} 308 \mathrm{E} & \text { Wang et al. (1993a) } \\ 15 & \text { Kunming } & (29) & 356 / 7 & 7.9 & 69 \mathrm{~N} 293 \mathrm{E} & \text { Fang et al. (1989b) }\end{array}$

\section{Other Late Permian and Triassic sedimentary rocks}

$\begin{array}{llcrrrl}16 & \text { Hunan Tr1 } & (15) & 53 / 28 & 5.7 & 40 \mathrm{~N} 205 \mathrm{E} & \text { Dobson and Heller (1992) } \\ 17 & \text { Huachi Tr2 } & 8 & 216 /-26 & 7.5 & 64 \mathrm{~N} 221 \mathrm{E} & \text { Chan et al. (1984) } \\ 18 & \text { Yelang Tr1 } & 9 & 40 / 13 & 11.0 & 46 \mathrm{~N} 219 \mathrm{E} & \text { Opdyke et al. (1984) } \\ 19 & \text { Hechuan Tr1 } & (62) & 50 / 17 & 4.1 & 39 \mathrm{~N} 210 \mathrm{E} & \text { Steiner et al. (1989) } \\ 20 & \text { Sichuan Tr1 } & - & 36 / 14 & 5.0 & 48 \mathrm{~N} 225 \mathrm{E} & \text { Heller et al. (1989) } \\ 21 & \text { Xuanwei P2 } & - & 24 /-2 & - & 52 \mathrm{~N} 243 \mathrm{E} & \text { McElhinny et al. (1981) } \\ 22 & \text { Shangsi P2 } & 38 & 36 / 12 & 2.1 & 47 \mathrm{~N} 226 \mathrm{E} & \text { Steiner et al. (1989) } \\ 23 & \text { Sichuan P2/Tr1 } & 5 & 46 / 12 & 8.7 & 40 \mathrm{~N} 214 \mathrm{E} & \text { Enkin et al. (1992) }\end{array}$

No. corresponds to locality labels of Figure 1 and pole lable labels of Figure 8 .

$N$ - number of sites, $n=$ number of samples, $A_{95}$ is the statistical parameter associated with the mean.

\# Recalculated data, consisting of both results $5(\mathrm{R})$ and $5(\mathrm{~N})$ in Figure 1, see group 1 in Table 4 for details and text for discussion.

* Recalculated data, see Table 3 for details and text for discussion. 
that their normal polarities have reduced the possibilities that they are Kiaman in age. In a recent paper, Van der Voo et al. (1993) report paleomagnetic results from the Emeishan Basalts near Kunming, accompanied by electron microscopic observations of the thin-sections, and observed that apparently primary magnetizations with cast-northeasterly/west-southwesterly directions and secondary magnetizations with northerly directions have been revealed by these rocks. These observations have clarified the paleopole situation for the latest Permian of South China, but demonstrate that almost all of the Permian data, which have been obtained from the Emeishan basalts, show considerable complexity in magnetizations. A paleomagnetic study of sedimentary rocks with ages similar to those of the Emeishan Basalts in South China, therefore, still appears to be necessary to clarify the Late Permian pole. In order to contribute towards a resolution of this issue, we report here on the results of a collection of 24 limestone samples from 4 sites in the uppermost part of the Maokou Formation (bottom section of the Upper Permian in the SCB) in Zhijin County of Guizhou province.

We also re-analyze the published Emeishan directions in an attempt to fine-tune the paleopole analysis. It is essential, for instance, that the characteristic sample directions in a site or the site mean directions in a formation be logically grouped, i.e., only directions representing the same magnetization can be aggregated into the same group. We have noticed that such grouping techniques have not been handled properly in some previous studies of the Emeishan Basalts at the localities other than the stratotype section in Emei County; this has obscured in our opinion the true nature of the results reported. On the other hand, it is remarkable that the magnetization behavior in the Emei stratotype section, where only the normal-polarity directions have been resolved (McElhinny et al., 1981; Chan et al., 1984; Zhang, 1984; Zhao and Coe, 1987), is simpler than that of the other sections. A review of the previously published data from the Emeishan Basalts in the non-stratotype sections indicates that more than one characteristic magnetization component can be resolved in several lo-
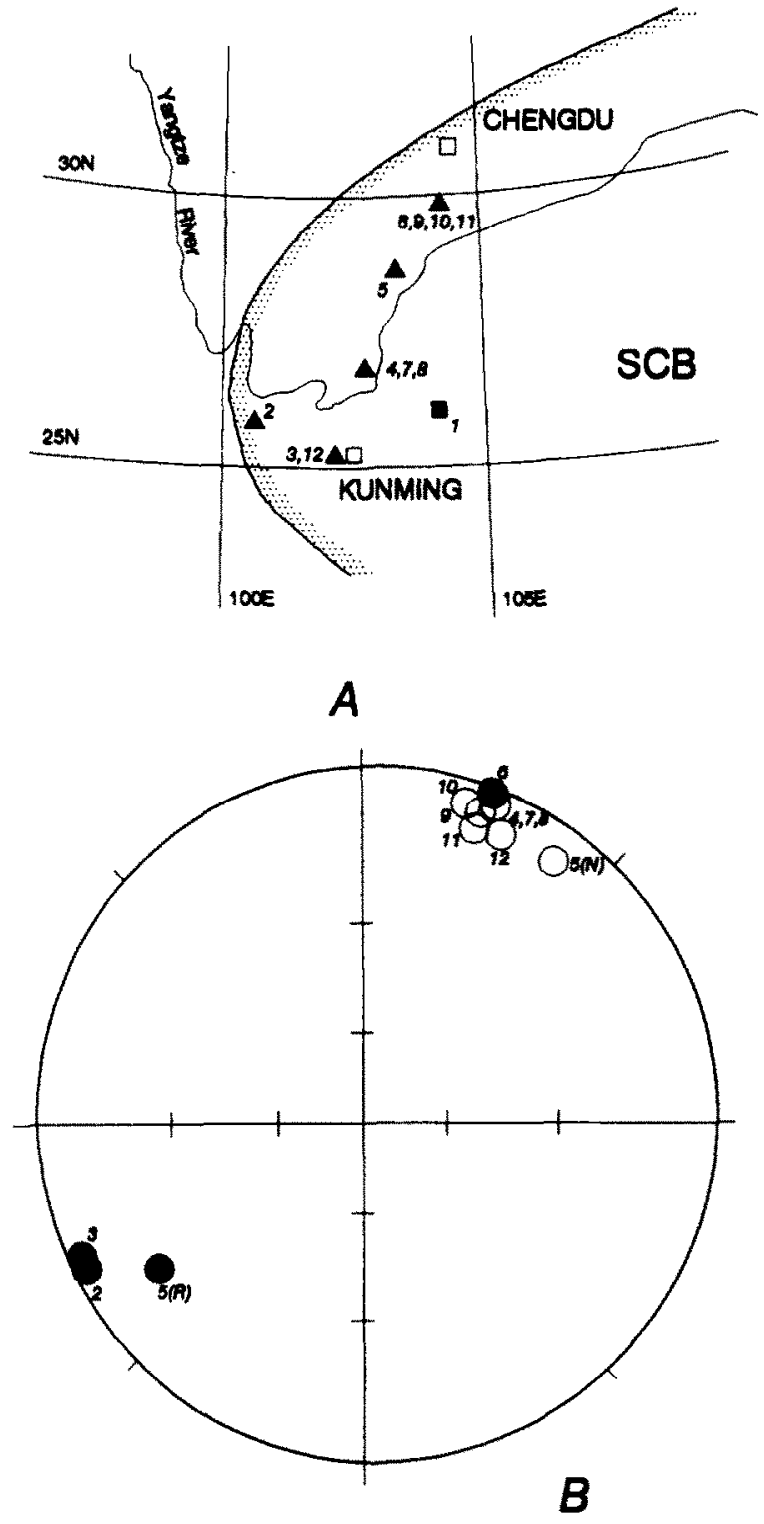

Fig. 1. Sampling areas and normal- and reversed-polarity directions in equal-area projection obtained from previous studies of the Late Permian Emeishan Basalts. Studies are identified by the same number as in Table 1. Note that some of the data in Table 1 have been recalculated, while all the directions in Figure 1B are extracted from original paper: the results labeled $4,7,8$ in Table 1 were combined to report a final mean (the direction labeled $4,7,8$ in Fig. 1B) by Huang et al. (1986); both reversed and normal directions reported by Zhou et al. (1986) $(S(R)$ and $5(N)$ in Fig. 1B, respectively) are averaged to give a result numbered 5 in Table 1 . Solid square in the locality map indicates the sampling area of this study. Open symbols in Figure 1B represent upper hemisphere projections; closed symbols represent lower hemisphere projections. $S C B=$ South China Block. 
calities (e.g., Dongchuan, Huang et al., 1986 and Panxi, Zhou et al., 1986). Re-analysis of the data from these localities, along with our results from the limestones in Zhijin County, leads to a plausible constraint on the arguments about the nature of the magnetizations in the Emeishan Basalts. In our interpretation, we attempt to construct a new apparent polar wander path for the South China Block during the latest Paleozoic/early Mesozoic period.

\section{Geology and sampling}

The Zhijin Permian section including the Maokou Formation is located in Guizhou province, in the southwestern part of the South China Block (solid square in Fig. 1). The Maokou Formation, consisting of fossiliferous marine platform limestones, has well constrained ages correlating with the early Kungurian to late Kazanian Permian stages of the western world (Yang et al., 1986). The DNAG time scale (Palmer, 1983) assigns an age range of about $263 \mathrm{Ma} / 253 \mathrm{Ma}$ for this period. Our sampling location is in the middle of the Maokou Formation, with an age roughly equivalent to Ufimian (the beginning of the Late Permian), slightly older than the Emeishan Basalts. This age overlaps with the end of the Kiaman superchron (Creer et al., 1971). The strata dip gently or moderately to the northeast (12-33 degrees) and are unmetamorphosed.

A total of 24 individual oriented samples distributed at 4 sites were collected from fresh roadcuts, using a portable gasoline-powered drill and a magnetic compass. All $2.5-\mathrm{cm}$ diameter samples drilled in the field were cut into $2.2-\mathrm{cm}$ height. The bedding attitudes are summarized in Table 2 along with the paleomagnetic results obtained.

\section{Paleomagnetic results}

Measurements were carried out on a ScT cryogenic magnetometer, with $\mathrm{AF}$ and thermal demagnetizations performed by Schonstedt equipment at the University of Michigan, in a shielded room with rest field less than $250 \mathrm{nT}$. Demagnetization results have been plotted in orthogonal vector diagrams (Zijderveld, 1967) and in stereographic projections from which components of magnetizations were recognized, followed by Principal Component Analysis (Kirschvink, 1980). The NRM intensities of the samples ranged between 0.1 and $1.2 \mathrm{~mA} / \mathrm{m}$. AF treatment did not succeed in reducing the intensity to a small percentage of the initial NRM, so stepwise thermal demagnetization has been used on all of the samples. The results described below for the Maokou Formation of the Zhijin section have been summarized in Table 2 .

A rather straightforward demagnetization behavior has been found in almost all of the samples. After removal of an occasional spurious magnetization which has a random direction in the initial stages of demagnetization, the dominant (characteristic) magnetization component is revealed in 21 out of total 24 samples (Fig. 2). The characteristic component in the majority of samples is of normal polarity, with a northeast-

TABLE 2

Paleomagnetic results from Upper Permian limestones in Zhijin, Guizhou province

\begin{tabular}{llllllllc}
\hline Site & ST/DP & $n / N$ & $\begin{array}{l}\text { In-situ } \\
\mathrm{D} / \mathrm{I}\end{array}$ & $\begin{array}{l}\text { Tilt-corrected } \\
\mathrm{D} / \mathrm{I}\end{array}$ & $k_{2}$ & $a_{95}$ & $k_{2} / k_{1}$ & $\begin{array}{l}\text { Pole } \\
\text { Long } / \text { Lat }\end{array}$ \\
\hline P1 & $36 / 33$ & $6 / 7$ & $41 / 18$ & $50 / 13$ & 25.6 & 13.7 & - & - \\
P2 & $23 / 12$ & $6 / 6$ & $38 / 13$ & $40 / 9$ & 16.4 & 17.1 & - & - \\
P3 & $10 / 25$ & $4 / 5$ & $56 / 21$ & $59 / 2$ & 19.3 & 21.5 & - & - \\
P4 & $18 / 33$ & $5 / 6$ & $50 / 41$ & $65 / 19$ & 55.0 & 10.4 & - & - \\
mean & - & $4 / 4$ & $46 / 23$ & $53 / 11$ & 40.0 & 14.7 & 1.27 & $208 / 34$ \\
\hline
\end{tabular}

ST/DP indicates bedding orientation; $n / N$ indicates number of samples used to calculate the mean/number of the samples demagnetized.

$k_{2} / k_{1}$ is the ratio of precision parameters after/before correction for bedding tilt. 

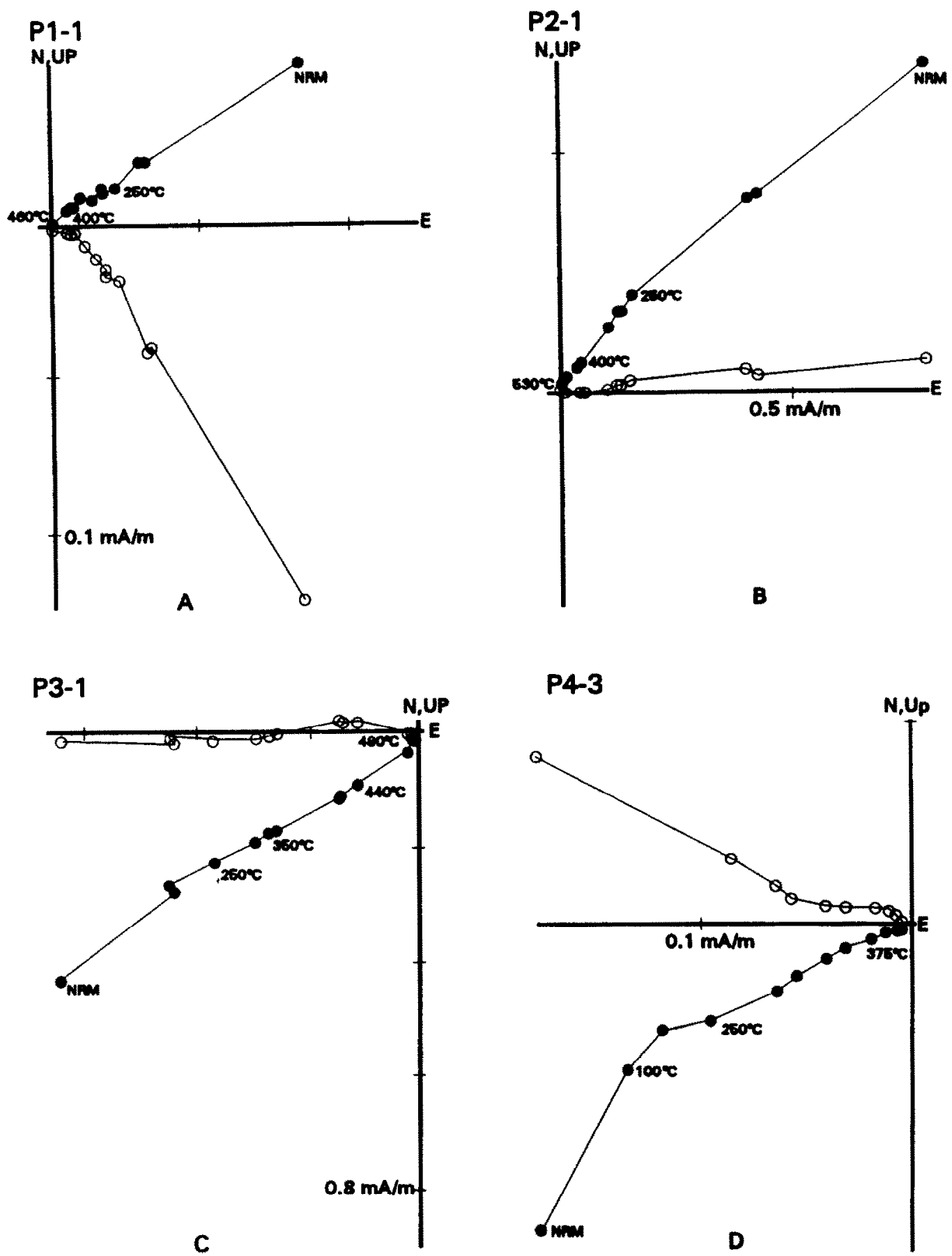

Fig. 2. Orthogonal demagnetization diagrams representative of samples displaying characteristic directions in tilt-corrected coordinates. Open circles represent end points plotted in vertical projection; solid circles represent end points plotted in horizontal projection. Numbers with degrees adjaccnt to data points are thermal demagnetization levels in ${ }^{\circ} \mathrm{C}$. (A and B) Characteristic directions showing normal polarities. $(\mathrm{C}$ and $\mathrm{D})$ Characteristic directions showing reversed polarities.

erly shallow direction (Figs. $2 \mathrm{~A}$ and $2 \mathrm{~B}$ ). Only two individual samples in two sites show reversed-polarity directions which appear to be an- tipodal to the normal-polarity directions in the other samples (Figs. 2C and 2D). The in-situ directions of the characteristic components are 


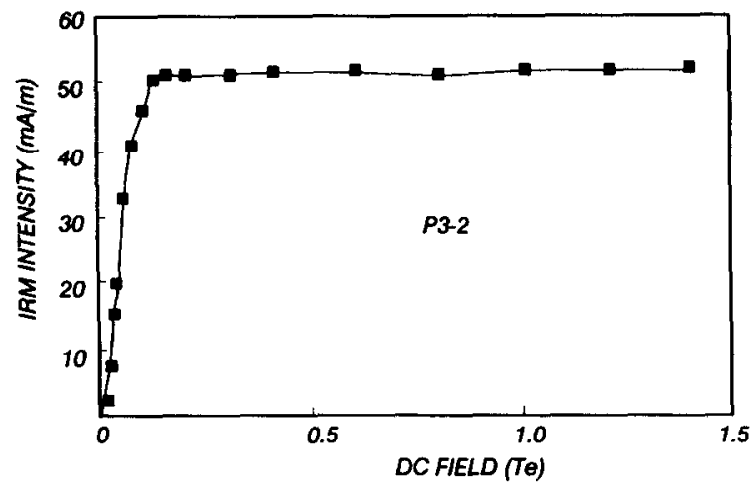

Fig. 3. An IRM acquisition curve indicating a saturation DC field of 0.2 teslas, suggesting that the magnetization of this sample is carried by magnetite.

significantly different from the present-day field direction and, therefore, represent ancient magnetizations. The unblocking temperatures (uniformly below $550^{\circ} \mathrm{C}$ ) imply that this component resides in magnetite only, which is also confirmed by IRM acquisition curves (e.g., Fig. 3) where the magnetization is saturated at a DC field of about 0.2 teslas.

The characteristic directions of the individual samples of the Maokou limestones are illustrated in Figure 4; the site and formation means are listed in Table 2. The directions appear to be well grouped and the average result should represent an ancient geomagnetic field in South China. A positive reversal test, according to a model proposed by McFadden (1990), can be obtained for these directions. The precision parameter $(k)$ of the formation mean is slightly increased after correction for bedding tilt $\left(k_{2} / k_{1}=1.27\right)$ (Table 2) although this does not indicate a positive fold test at a high significance level. The timing of the magnetization acquisition, however, remains uncertain. The Maokou limestones have ages near the end of the Kiaman superchron. The dominantly normal polarity thus could indicate a secondary nature for the characteristic magnetization components. This suspicion is supported by observations of the magnetic carriers of the samples. Scanning electron microscopy of several polished thin-sections revealed that the occurence of magnetite is always associated with pyrite, forming framboidal (Fig. 5A) or rimmed structures (Fig. 5B) in the calcite matrix, which is reminiscent of what has been observed in the remagnetized limestones in North America (Suk et al., 1990) and suggests a diagenetic (chemical) origin for the magnetite.

A discussion on the magnetization age of the characteristic component will be given in further detail in the section following a review of the paleomagnetic data from the Emeishan Basalts.

\section{Previous results from the Emeishan Basalts - a review}

Several previously published studies have obtained coherent characteristic magnetizations with

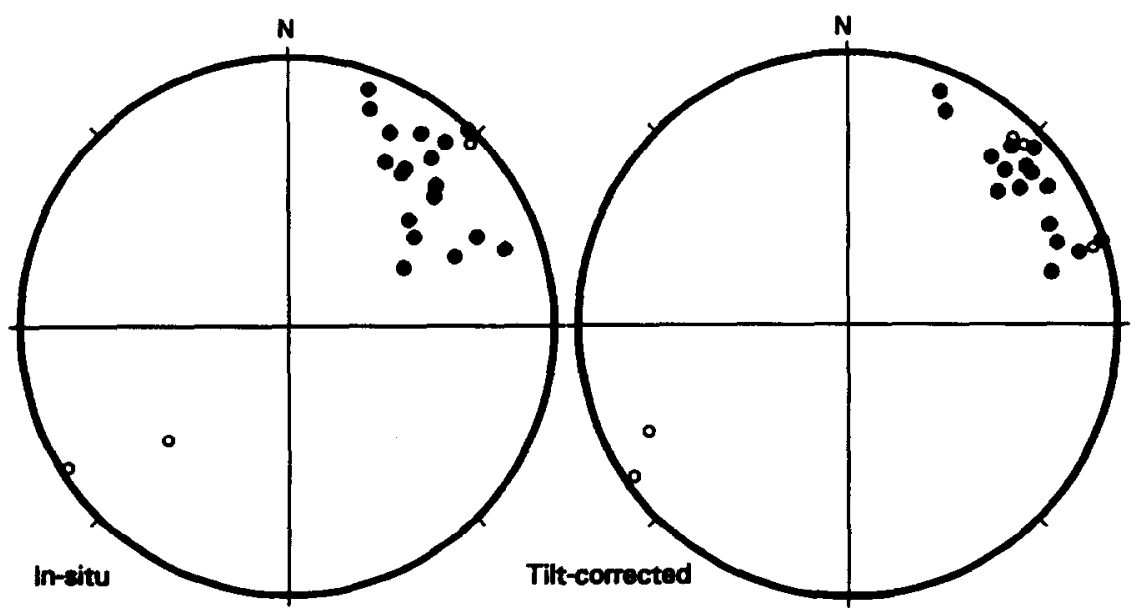

Fig. 4. Equal-area projections of the sample directions of the characteristic components isolated from the Upper Permian limestones before (left) and after (right) correction for bedding tilt. Note that reversed directions are observed in two samples. Open symbols represent upper hemisphere projections; closed symbols represent lower hemisphere projections. 

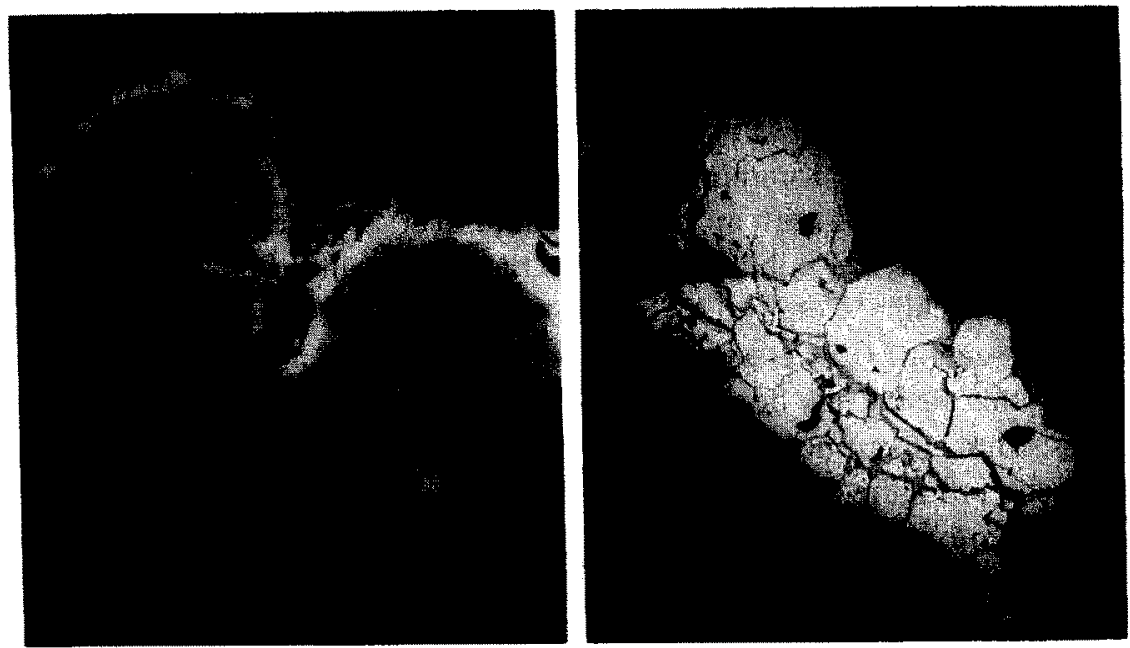

Fig. 5. Secondary-electron images of representative opaque grains in the polished thin-sections of the Permian limestones. Left: magnetite that replaced framboidal pyrite; bright cores of some crystals are relict pyrite (white arrows). Right: pyrite (bright part) rimmed by magnetite (grey rims). Both features indicate a diagenetic origin for the magnetite. Scale bar: left, $8 \mu \mathrm{m}$; right, $35 \mu \mathrm{m}$.

north-northeasterly shallow directions from the Emeishan Basalts in the Emei stratotype section south of the city of Chengdu (McElhinny et al,, 1981; Chan et al., 1984; Zhang, 1984; Zhao and Coe, 1987) (see Figure 1 for locality and Table 1 for results). However, there are some surprising variabilities in the magnetizations of the emeis- han basalts studied in other areas (Huang et al., 1986; Zhou et al., 1986; Van der Voo et al., 1993), where dual-polarity directions have been observed and the overall directions show a large divergence. Van der Voo et al. (1993) reported a well defined mean normal-polarity direction, from the majority of samples, conforming to the char.

\section{TABLE 3}

Paleomagnetic results from the Emeishan Basalts in Dongchuan, Yunnan province (after Huang et al., 1986*)

\begin{tabular}{|c|c|c|c|c|c|c|}
\hline Site & $n(N)$ & $\begin{array}{l}\text { In-situ } \\
D / I\end{array}$ & $\begin{array}{l}\text { Tilt-corrected } \\
\text { D/I }\end{array}$ & $k$ & $a_{95}$ & $\begin{array}{l}\text { Pole } \\
\text { Long/Lat }\end{array}$ \\
\hline \multicolumn{7}{|l|}{ Group I } \\
\hline 14 & 5 & $79 /-31$ & $51 /-22$ & 1280 & 2.0 & - \\
\hline 15 & 4 & $90 /-32$ & $55 /-33$ & 130 & 8.1 & - \\
\hline Mean Group 1 & (2) & $85 /-32$ & $53 /-26$ & - & - & $224 / 25$ \\
\hline \multicolumn{7}{|l|}{ Group 2} \\
\hline 12 & 4 & $44 /-45$ & $23 /-6$ & 106 & 9.0 & - \\
\hline 17 & 5 & $228 / 19$ & $218 / 7$ & 935 & 2.5 & - \\
\hline 19 & 5 & $30 /-33$ & $17 /-8$ & 568 & 3.2 & - \\
\hline Mean Group 2 & (3) & $45 /-32$ & $24 /-7$ & 55 & 16.0 & $241 / 52$ \\
\hline \multicolumn{7}{|l|}{ Group 3} \\
\hline 13 & 4 & $193 /-6$ & $211 /-48$ & 2974 & 1.7 & - \\
\hline 16 & 4 & $14 /-15$ & $18 / 30$ & 399 & 4.6 & - \\
\hline 18 & 4 & $180 /-11$ & $192 /-44$ & 571 & 3.2 & - \\
\hline Mean Group 3 & (3) & $189 /-1$ & $(201 / 41)$ & 47 & 18.1 & $265 / 62 *$ \\
\hline
\end{tabular}

* Calculated from the in-situ direction; $n(N)$ is the number of samples (sites) used to calculated the mean;

* In the original paper, the mean directions of all the 8 sites have been grouped together to calculate the formation mean. Parentheses indicate (not used). 
acteristic directions of the Emei stratotype sections, and a reversed direction (west-southwesterly and shallow downwards from two samples) in one site collected in the vicinity of Kunming city. Another reversed-polarity direction with an intermediate downward inclination was published for the Emeishan Basalts in Zhijin County $(30 \mathrm{~km}$ north of our sampling section) (Lin et al., 1985; Lin, 1989). However, this result has been based on only five samples. Thus, it can not be seen as reliable. As can be seen in Figure 1B, the normal and reversed directions are far from antipodal. It is this problem which we will primarily address in the following.

Huang et al. (1986) investigated three sections in Yunnan province. Exclusively normal characteristic directions have been observed from the Huidong section, whereas the Bingchuan section is entirely of reversed polarity. The site mean directions of the third section at Dongchuan, are listed in Table 3 and illustrated in Figure 6. It is rather striking that the individual directions in each of the sites are well grouped, as reflected by the confidence cones of less than 10 degrees, but the site mean directions are significantly scattered. This could be taken to suggest that different sites have recorded, or been affected by, different geomagnetic signals. A close look at the site mean directions reveals that they fall into three groups (1,2, and 3 in Fig. 6). For this grouping, one reversed direction in group 2 and two in group 3 have been inverted in Figure 6. If one treats, as the original paper did, all eight site means as representing the same geomagnetic field and averages them to obtain a formation mean, the result will be of little significancc. Wc arguc instead that the group 1 directions are equivalent, except for the polarity, to the reversed directions observed near Kunming by Van der Voo et al. (1993) and at Bingchuan by Huang et al. (1986). These directions are herein called the A directions and the corresponding pole positions are called A poles. The group 2 directions in Figure 6 , on the other hand, conform to the characteristic directions of the Emei stratotype sections which are herein labeled direction B. A paleopole calculated from the group 3 directions falls in the vicinity of the Cretaceous pole for the South China Block when the directions are tiltcorrected or in the vicinity of a Late TriassicJurassic pole that we obtained from remagnetized Paleozoic and Triassic sections of South China (Wang and Van der Voo, 1993; Wang et al., 1993a,b) when using in-situ coordinates. It is thus likely that the directions of the third group must be regarded as remagnetized in Mesozoic time and not as Permian magnetizations.

Another study was carried out by Zhou et al. (1986) and has yielded five individual site mean directions from four geographically spread locali-

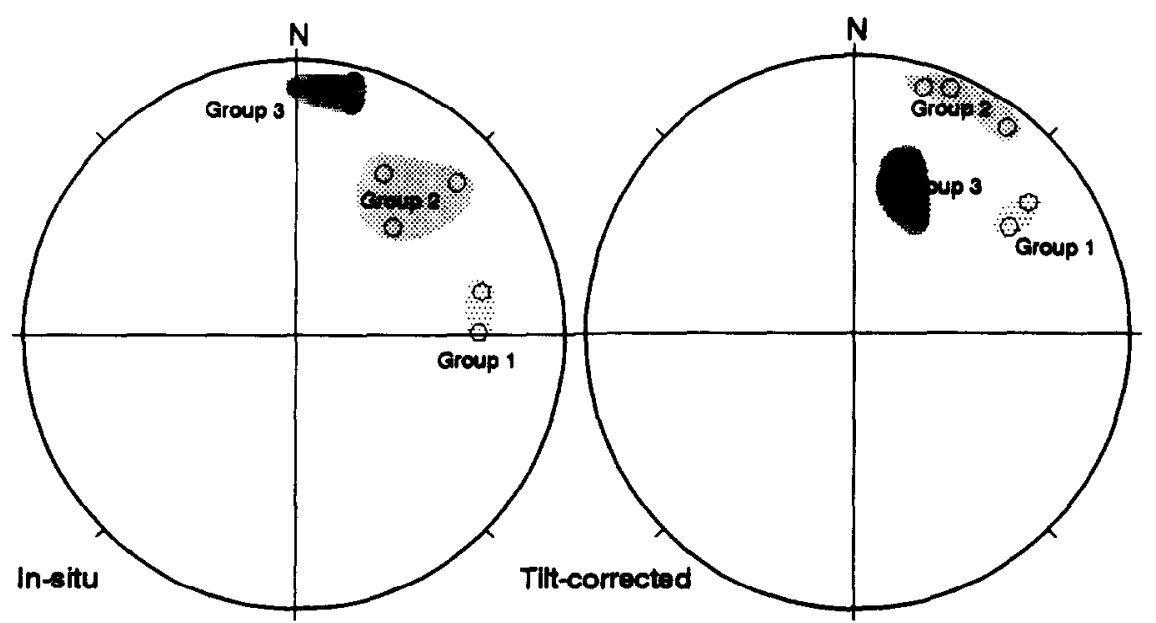

Fig. 6. Equal-area projections of the site mean directions reported by Huang et al. (1986) from the Emeishan Basalts in Dongchuan city of Yunnan province, before (left) and after (right) correction for bedding tilt. These directions had all been grouped together to calculate the formation mean in their paper. However, three directional populations, possibly representing different magnetizations, can be clearly seen in this diagram. For a re-analysis of these data, see text. 


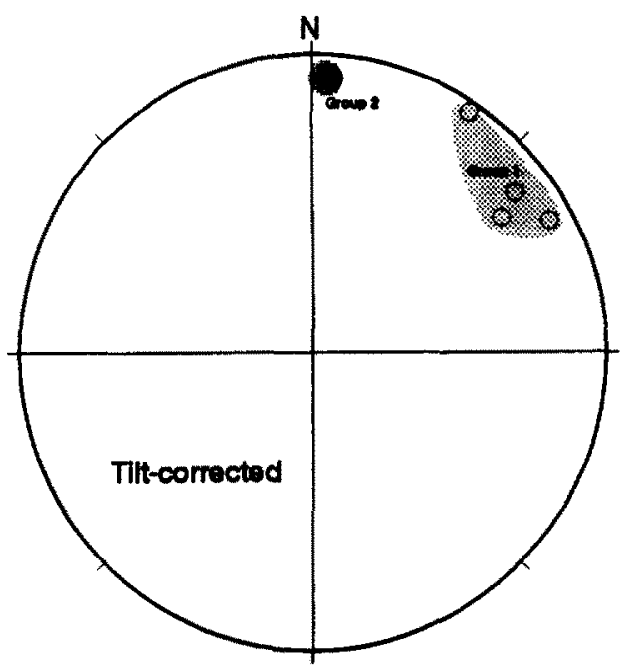

Fig. 7. Equal-area projection of the site mean directions reported by Zhou et al. (1986) from the Emeishan Basalts in the Panxi area of Sichuan province, after correction for bedding tilt. Note that the mean direction of one site (labeled Group 2) is significantly different from those of the other sites (labeled Group 1) and should probably not be included in the calculation of the formation mean.

ties in the Panxi area of Sichuan province. The results, including one reversed and four normal directions, are summarized in Table 4 and illustrated in Figure 7 (where the reversed polarity has been inverted). It is clear that the directions fall into two groups. Group 1, consisting of three normal and one reversed directions, resembles the A direction defined earlier; "group 2", with only one direction but significantly away from those of group 1, represents a different geomag- netic field [(most likely the same field as represented by the remagnetizations of Wang and Van der Voo (1993) and by the third group of directions of Huang et al. (1986)].

While Huang et al. (1986) combined all their site means to calculate a formation mean for the Dongchuan section, Zhou et al. (1986) grouped the directions from the Panxi section in terms of polarities. We argue that the averaged paleomagnetic poles reported for these two sections have little validity.

We conclude that three groups of directions, representing three different times of magnetization acquisition, are observed in the Emeishan Basalts of the South China Block. Groups B and A display north-northeasterly and east-northeasterly shallow directions, respectively. Both groups show mixed polarities. The magnetization ages of these two groups of directions will be discussed in the following section. The third (northerly) group of directions is most likely a younger, Mesozoic remagnetization.

\section{Interpretation and discussion}

The paleomagnetic data from the Emeishan Basalts and the Late Permian Maokou limestones in Zhijin County are summarized in Table 1. The directions resolved from the Maokou limestones fall into the A group for the Emeishan Basalts. It has been mentioned earlier that the characteristic magnetizations of the Maokou formation show

\section{TABLE 4}

Paleomagnetic results from the Emeishan Basalts in Panxi, Sichuan province (after Zhou et al., 1986*)

\begin{tabular}{|c|c|c|c|c|c|c|}
\hline Site & $n(N)$ & $\begin{array}{l}\text { In-situ } \\
\mathrm{D} / \mathrm{I}\end{array}$ & $\begin{array}{l}\text { Tilt-corrected } \\
\text { D/I }\end{array}$ & $k$ & $a_{95}$ & $\begin{array}{l}\text { Pole } \\
\text { Long/Lat }\end{array}$ \\
\hline \multicolumn{7}{|l|}{ Group I } \\
\hline Meigu2 & 10 & - & $33 /-3$ & 7.5 & 19 & - \\
\hline Miyil & 8 & - & $61 /-9$ & 37.9 & 9 & - \\
\hline Miyi2 & 11 & - & $52 /-14$ & 51.1 & 6 & - \\
\hline Miyi3 & 12 & - & $235 / 23$ & 24.4 & 9 & - \\
\hline Mean group 1 & (4) & - & $50 /-12$ & 32.0 & 16 & $218 / 31$ \\
\hline \multicolumn{7}{|l|}{ Group 2} \\
\hline Meigu1 & 10 & - & $3 /-9$ & 15.5 & 13 & $277 / 57$ \\
\hline
\end{tabular}

$n(N)$ is the number of samples (sites) used to calculated the mean;

* In the original paper, the mean directions of all the 5 sites have been grouped togethert to calculate the formation mean. 
evidence of being remagnetized. Considering that the Emeishan Basalts are slightly younger than the Maokou limestones studied, it seems reasonable and logical to infer that the characteristic magnetization of the Maokou limestones has the same acquisition age as that of the group $A$ magnetization in the Emeishan Basalts. Thus we will include the Maokou limestone directions in group $A$ in further discussion.

Thin-section SEM and STEM images provided by Van der Voo et al. (1993) indicated that cruciform magnetite extensively resides in two Emeishan Basalt samples showing the group A directions (i.e., west-southwesterly and northeasterly directions, respectively), suggesting that these two samples may well carry primary magnetizations. For thin-sections of two other samples representative of those displaying the group B directions (i.e., north-northeasterly), however, SEM observations show distinctive textures with magnetite and sphene replacing titanomagnetite as a result of hydrothermal alteration (Van der Voo et al.,
1993). This provides solid evidence for remagnetization of the group B directions in the Emeishan Basalts.

From these observations, as well as our reanalysis of the directions of Huang et al. (1986) and Zhou et al. (1986), it has now become clear that the group A directions represent primary magnetizations of the Emeishan Basalts whereas group B is secondary. The question thus arises: why were some of the samples/sites remagnetized but others not, considering that both $\mathrm{A}$ and $B$ directions have been observed at the same locality (e.g., Zhou et al., 1986) or even at the same site (e.g., Van der Voo et al., 1993)? Selected pathways for migration of fluids could be a possible reason, although the ultimate answer will certainly depend on further detailed investigation.

Pole positions calculated from the group A directions are shown in Figure 8 as a cluster labeled A; individual results are labeled according to the numbers listed in Table 1 . The seven

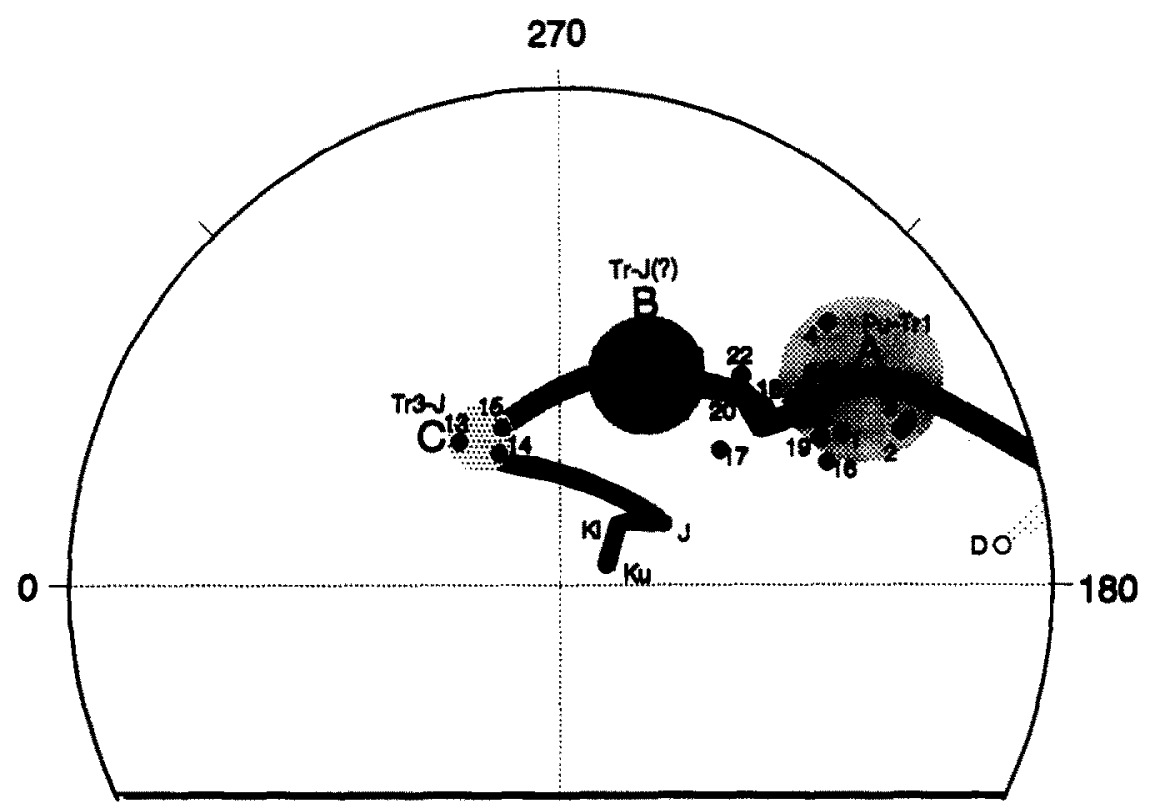

Fig. 8. A new post Devonian Apparent Polar Wander Path for the South China Block, indicating rapid apparent polar wander for South China during the late Paleozoic and early Mesozoic. $K u=$ Late Cretaceous (Kent et al., 1986); $K l=$ Early Cretaceous (Lin, 1984); $J=$ Jurassic (Huang et al., 1991); Tr.3.I = I ate Triassic to Jurassic. Paleopoles obtained from the Emeishan Basalts and the limestones of this study, which fall into two groups, $\mathrm{A}$ and $\mathrm{B}$, are plotted with numbering labels which are identified in Table 1; Group C paleopoles as well as the poles obtained from other Late Permian and Early Triassic sedimentary rocks in South China are also plotted with numbering labeis corresponding to those in Table 1. The APWP, as plotted, suggests that cluster A represents Late Permian (generally primary) poles for South China while the B poles have an apparently age confined to be younger than Late Triassic but older than late Jurassic. See text for discussion. 
pole positions clustered in $\mathrm{B}$ are based on the group $\mathrm{B}$ directions in Table 1 . Three $\mathrm{C}$ poles are plotted according to the Group $\mathrm{C}$ data in Table 1. Also included in Figure 8 are the paleopoles obtained from other Late Permian and Triassic sedimentary rocks thus far for the South China Block, including one reported recently for the Early Triassic by Dobson and Heller (1992) and one for the Late Permian / Early Triassic by Enkin et al. (1992). It is striking that these poles fall well on a path from cluster A to cluster B. A mean Early Triassic pole for South China can be calculated by averaging individual poles labeled 16 through 21 in Table 1 and Figure 8, assuming that they are all primary.

If we accept the validity of the Devonian, Triassic and Late Triassic/Jurassic poles (Group C) for South China, the A and B poles fall on the APWP segments between the Devonian and Triassic poles and between the Triassic and Triassic/Jurassic poles, respectively (Fig. 8). Considering the mixed polarities for poles $\mathrm{A}$ and $\mathrm{B}$, they must both be younger than the Kiaman superchron. The titaniferous magnetite carrying the magnetization of the $A$ poles in the Yunnan Emeishan Basalts (Van der Voo et al., 1993) suggests that these poles are most likely representative of the Latest Permian field in South China (i.e., primary). In the absence of obvious evidence for an appropriate age of the $B$ poles, on the other hand, it appears reasonable to consider that the $\mathrm{B}$ poles are based on remagnetizations acquired during the interval between Early Triassic and Early Jurassic. The apparent polar wander path for the South China Block thus has a long and sinuous, but systematically younging trend, as shown in Figure 8, indicating that the South China Block experienced a rapid clockwise rotation (about $60^{\circ}$ ) during the latest Paleozoic and early Mesozoic.

In our analysis of the variable (A, B, C) directions observed in South China, we have considered whether relative rotations between sampling localities could explain the differences, which are primarily in the declinations. However, several lines of argument allow us to reject such rotations as a systematic cause of the declination variations between about $60^{\circ}$ (Group $\mathrm{A}$ ), about $20^{\circ}$ (Group
B) and about $350^{\circ}$ (Group C): (1) the $\mathrm{A}$ and $\mathrm{B}$ directions occur in the same site (Van der Voo et al., 1993); (2) the A and B directions are observed in widely separated regions (Guizhou, Yunnan, Sichuan, Hunan); and (3) the $\mathrm{C}$ directions are also derived from all corners of the South China Block (Jiangsu, Guizhou, Yunnan).

\section{Conclusions}

(1) A characteristic magnetization component with an east-northeasterly shallow direction has been resolved from the Maokou limestones in Zhijin County of Guizhou province. SEM obscrvations indicate a secondary origin for the magnetic carrier of this component. We suggest that this magnetization was acquired during the latest Permian.

(2) A review of previously published paleomagnetic data from the Emeishan Basalts in South China reveals that two magnetization components reside in the basalts. One component, $\mathrm{A}$, has a direction closely resembling that observed in the Maokou limestones. The other component, B, displays a similar inclination to, but a different declination from, that of component A. SEM observations of Emeishan Basalts thin-sections indicate that the $\mathrm{A}$ group directions most likely represent the primary magnetizations, while the $\mathrm{B}$ group directions are remagnetizations.

(3) Based on the paleomagnetic data obtained from the Emeishan Basalts and the Maokou limestones, a long and sinuous latest Paleozoic/early Mesozoic apparent polar wander path can be constructed for South China, indicating that the South China Block experienced a large clockwise rotation (about $60^{\circ}$ ) during that time.

\section{Acknowledgement}

Wc thank the staff at the Guizhou Geological and Mineral Resources Bureau for helping with sample collection. We thank Prof. D.R. Peacor for valuable discussions on electron microscopy work. This research was supported by the National Science Foundation, grants EAR 88-16772 and EAR 89-15705. 


\section{References}

Chan, L.S., Wang, C.Y. and Wu, X.Y., 1984. Paleomagnetic results from some Permian-Triassic rocks from southwestern China. Geophys. Res. Lett., 11: 1157-1160.

Creer, K.M., Mitchell, J.G. and Valencio, D.A., 1971. Evidence for normal geomagnetic polarity at $263 \pm 5$ m.y.B.P. within the late Paleozoic reversed interval. Nature, 233: $87-89$.

Dobson, J. and Heller, F., 1992. Triassic paleomagnetic results from the Yangtze Block, S.E. China. Geophys. Res. Lett., in press.

Enkin, R.J., Courtillot, V., Leloup, H., Yang, Z., Xing, L., Zhang, J. and Zhuang, Z., 1992. The paleomagnetic record of uppermost Permian and Lower Triassic rocks from the South China Block. Geophys. Res. Lett., 19: 2147-2150.

Fang, W., Van der Voo, R. and Liang, Q., 1989a. Devonian paleomagnetism of Yunnan Province across the Shan Thai-South China suture. Tectonics, 8: 939-952.

Fang, W., Van der Voo, R. and Liang, Q., 1989b. Reconnaissance magnetostratigraphy of the Precambrian-Cambrian boundary section at Meishucun, China. Cuad. Geol. Iber., 12: 205-221.

Heller, F., Lowrie, W., Li, H. and Wang, J., 1988. Magnetostratigraphy of the Permo-Triassic boundary section at Shangsi, China. Earth Planet. Sci. Lett., 88: 348-356.

Huang, K.N., Opdyke, N.D., Xu, G.Z. and Tang, R.L., 1986. Further paleomagnetic results from the Permian Emeishan Basalt in SW China, Kexue Tongbao (English trans.), 31: 1195-1201.

Huang, K.N. and Opdyke, N.D., 1991. Paleomagnetism of Jurassic rocks from southwestern Sichuan and the timing of the closure of Qinling Suture. Tectonophysics, 200: 299-317.

Kent, D.V., Xu, G., Huang, K., Zhang, W.Y. and Opdyke, N.D., 1986. Paleomagnetism of Upper Cretaceous rocks from South China. Earth Planet. Sci. Lett., 79: 184-189.

Kent, D.V., Zheng, X.S., Zhang, W.Y. and Opdyke, N.D., 1987. Widespread Mesozoic to Recent remagnetization of Paleozoic and Triassic sedimentary rocks from South China. Tectonophysics, 139: 133-143.

Kirschvink, J.L., 1980. The least-squares line and plane and the analysis of paleomagnetic data. Geophys. J.R. Astron. Soc., 62: 699-718.

Li, C., Wang, Q., Liu, X.Y. and Tang, Y.Q., 1982. Explanatory Notes to the Tectonic Map of Asia. Cartographic Publishing House of China, Beijing, $49 \mathrm{pp}$.

Lin, J.-L., 1989. Comments on the Permian paleomagnetic results from South China (in Chinese with English abstract). Geol. Rev., 35: 349-354.

Lin, J.-L., Fuller, M.D. and Zhang, W.Y., 1985. Preliminary Phanerozoic polar wander paths for the North and South China Blocks. Nature, $313 ; 444-449$.
McElhinny, M.W., Embleton, B.J.J., Ma, X.H. and Zhang, Z.K., 1981. Fragmentation of $A$ sia in the Permian. Nature, 293: 312-316.

McFadden, P.L., 1990. A new fold test for paleomagnetic studies. Geophys. J. Int., 103: 163-169.

Molina-Garza, R.S., Geissman, J.W. and Van der Voo, R., 1989. Paleomagnetism of the Dewey Lake Formation (Late Permian), northwest Texas: end of the Kiaman superchron in North America. J. Geophys. Res., 94: 17,881-17,888.

Opdyke, N.D., Huang, K., Xu, G., Zhang, W.Y. and Kent, D.V., 1986. Paleomagnetic results from the Triassic of the Yangtze Platform. J. Geophys. Res., 91: 9553-9568.

Palmer, A.R., 1983. The decade of North American geology (DNAG) 1983 geologic time scale. Geology, 11: 503-504.

Steiner, M., Ogg, J., Zhang, Z. and Sun, S., 1989. The Late Permian/Early Triassic magnetic polarity time scale and plate motions of South China. J. Geophys. Res., 94: 73437363.

Suk, D., Peacor, D.R. and Van der Voo, R., 1990. Replacement of pyrite framboids by magnetite in limestone and implications for paleomagnetism. Nature, 345: 611-613.

Van der Voo, R., Fang, W., Wang, Z, Suk, D., Peacor, D.R. and Liang, Q., 1993. Paleomagnetism and Electron Microscopy of the Emeishan Basalts, Yunnan, China. Tectonophysics, 221: 367-379.

Wang, Z. and Van der Voo, R., 1993. Pervasive remagnetization of Paleozoic rocks acquired at the time of Mesozoic folding in the South China Block. J. Geophys. Res., 98: $1729-1741$.

Wang, Z, Van der Voo, R. and Wang, Y., 1993a. A new Mesozoic apparent polar wander path for South China: Paleomagnetism of Middle Triassic Rocks from Guizhou Province. Earth Planet. Sci. Lett., 115: 1-12.

Wang, Z., Van der Voo, R. and Wang, Y., 1993b. Paleomagnetic results from Late Sinian/Early Cambrian rocks in Guizhou province, South China Block. Tectonophysics, in review.

Yang, Z.Y., Cheng, Y.Q. and Wang, H.Z., 1986. Geology of China. Oxford Press, London, 303 pp.

Zhang, Z.K., 1984. Sino-Korean blocks and Yangtze block as part of the Pacifica continent in the late Paleozoic (in Chinese with English abstract). Bull. Chin. Acad. Sci., 9: 45-54.

Zhao, X.X. and Coe, R.S., 1987. Paleomagnetic constraints on the collision and rotation of North and South China. Nature, 327: 141-144.

Zhou, Y.X., Lu, L.Z. and Zhang, B.M., 1986. Paleomagnetic polarity of the Permian Emeishan Basalt in Sichuan (in Chinese with English abstract). Geol. Rev., 32: 465-469.

Zijderveld, J.D.A., 1967. AC demagnetization of rocks: analysis of results. In: S.K. Runcorn, K.M. Creer and D.W. Collinson (Editors), Methods in Paleomagnetism. Elsevier, Amsterdam, pp. 254-286. 